\title{
The role of time in the relation between perceived job insecurity and perceived job performance
}

\author{
Patrick Pilipiec \\ Maastricht University, School of Business and Economics, Tongersestraat 53, 6211 LM Maastricht, \\ The Netherlands \\ E-mail: patrick.pilipiec@maastrichtuniversity.nl
}

Received 13 April 2019

Accepted 2 February 2020

\begin{abstract}
.
BACKGROUND: Insufficient evidence exists that can explain two conflicting views (i.e. positive and negative relationship) regarding the effect of job insecurity on job performance.

OBJECTIVE: To investigate the importance of time in explaining these ambiguous views. A positive association was expected cross-sectionally and a negative relationship longitudinally. I hypothesized that available coping resources may delay the negative effect on job performance until being exhausted.

METHODS: Longitudinal self-reported data of 928 participants were used. Job performance was operationalized as core task performance and productivity loss. Cross-sectional and longitudinal associations were analyzed using linear and logistic regressions. Duration analyses were performed using the two-year duration of job insecurity.

RESULTS: Short-term and long-term, job insecurity was only related with increased productivity loss. No evidence was found for core task performance. The duration of job insecurity, and chronic job insecurity in particular, did not predict core task performance or productivity loss two years later.

CONCLUSIONS: The factor time, operationalized as the time of follow-up and the duration of exposure to job insecurity, did not clarify the conflicting views. Managers should be more aware of the adverse effects of using job insecurity as a motivational strategy to increase job performance.
\end{abstract}

Keywords: Chronic exposure, core task performance, duration of job insecurity, productivity loss

\section{Introduction}

Globalization and competition have resulted in economic pressure for organizations to restructure their operations, and in a shift toward more flexible types of employment [1-3]. The resulting unstable and uncertain conditions may increase the worker's perceived job insecurity (hereafter job insecurity) [4-6]. Job insecurity refers to the experienced threat of involuntarily losing one's job [7, 8] and is identified in the European Union as a potential psychosocial occupational hazard $[9,10]$ that is likely to increase in the years to come $[11,12]$.

Studies consistently found job insecurity to be a major work stressor that has negative consequences on physical health, psychological well-being, and job attitudes such as organizational commitment and job satisfaction [13-21]. In addition, the finding that 
job insecurity is a stressor causing strain is in line with theoretical models such as the Job DemandsResources Model (hereafter JD-R Model) [22]. Job insecurity can be conceptualized subjectively (i.e. perceptions and feelings about the situation) and objectively (i.e. factual information about the situation) [23]. According to the literature, perceived job insecurity, instead of the objective situation, primarily influences attitudes and behaviors of employees [23]. Perceptions of fear and threat to job dismissal are therefore better anchored by the subjective approach and may not be captured by objective measurement [23-26]. Therefore, some workers may fear job loss while dismissal is objectively unlikely, others may feel confident that dismissal does not affect them personally while the firm is on the verge of a reorganization [20].

While the effects of job insecurity on health and well-being have been studied extensively, far less is known about the impact on perceived job performance (hereafter job performance) [3, 27]. Job performance refers to meeting predictable or formalized role requirements at the individual level [28, 29]. This conceptualization however differs from organizational commitment behaviors, where extra-role performance refers to performing courteous activities such as helping colleagues, which, although not directly formalized in job descriptions, are still invaluable to the firm [29]. Job performance can be assessed as the perceived judgment (e.g., overall quality and quantity of performed work) or as an objective measurement (e.g., the number of performed standardized acts) [30]. Researchers agree that objective measures may be unreliable, inconsistent, and may fail to assess the full range of work tasks and performance behaviors [30-32]. Therefore, these shortcomings make that perceived performance evaluations, while not perfect either, are often preferred [31-34]. Because employees are more likely to act according to their perception of their work environment, the subjective experience of job insecurity may therefore be an important determinant of job performance [35].

Given that job insecurity is projected to increase in subsequent years, understanding the relationship between job insecurity and job performance is crucial to maintain individual performance $[2,3]$, and for the continued existence, sustained competitiveness, and ongoing goal attainment of organizations [36]. However, to date, inconsistent associations have been found between job insecurity and job performance. For example, Gilboa et al. [13] reported a negative correlation, while no association was found by Sverke et al. [15]. In contrast, Probst [37] suggests that job insecurity may have a small positive influence, but at the cost of decreased quality of output.

In the literature, two conflicting views regarding the nature of the relationship between job insecurity and job performance exist that researchers have not yet been able to fully understand nor synthesize [27]. One stream of literature [38-40] argue for positive associations between job insecurity and job performance, suggesting that workers who experience job insecurity increase their job performance to avoid possible job loss [1]. This aligns with the "short-term managerial view", where managers may use job insecurity to motivate workers. Engaging in impression management tactics may be effective to reduce job insecurity and to socially influence the work environment, with the objective to control and diminish the risk of involuntary job loss [41]. On the other hand, various scholars have found negative associations that indicate that if one perceives a possible discontinuation of one's job, emotional and mental processes are triggered that drain the employee's energy and that deflect the worker's attention to regaining certainty, thereby decreasing performance $[12,13,16$, 42, 43]. In line with this perspective, managers should be more aware that job insecurity and low job performance are harmful to both the employee and organization [1, 11, 19, 41].

Overall, both views are inconsistent, but may be reconciled when taking the timeframe into account. Given the role of impression management, positive associations may reflect short-term effects, especially when investigated cross-sectionally. On the other hand, in line with the JD-R Model, it may require time for the stressor job insecurity to exhaust available coping resources and to develop a mental and emotional burden that exerts a negative effect on job performance. This implies that a prospective cohort design, which includes the measurement of job insecurity at baseline and that allows longitudinal analyses, is required to investigate the assumed long-term relationships accurately [44-47]. A serious shortcoming in the literature is however the study design, as associations between job insecurity and job performance are often only measured cross-sectionally [27]. Therefore, evaluating the role of time, by separating crosssectional associations and longitudinal relationships, may provide more clarity about these conflicting views. 
Furthermore, the duration of exposure to job insecurity, essentially another aspect of time, may provide more insight into these conflicting views. While job insecurity itself has been studied abundantly, longitudinal measurement of its duration remains scarce [48]. Selenko et al. [27] report that still no insight exists into the outcomes of long-term chronic job insecurity. Since the duration of exposure to job insecurity may vary, investigations using different time windows may yield incongruent and inconsistent results [48]. To address this shortcoming, Glavin [48] proposed that the nature and severity of healthrelated outcomes may be influenced by the length of exposure to job insecurity, and found evidence for decreased health among chronically exposed workers. To my awareness, the duration of such exposure has been studied scarcely, but not yet in relation with the outcome job performance. Therefore, in line with the JD-R Model, I posit that job performance is most negatively affected among chronic job insecure workers.

Hence, the purpose of this study was to investigate the importance of time in explaining the ambiguous views about the relationship of perceived job insecurity and perceived job performance. Two hypotheses were formulated to address two important shortcomings in the literature. First, I investigated the cross-sectional and longitudinal associations between job insecurity and job performance (operationalized as core task performance and productivity loss). I hypothesized a positive relation short-time, and a negative relation long-term. Second, I aimed to advance scientific knowledge by considering the effect of the duration of job insecurity, and propose that negative job performance is reflected most in workers who are chronically exposed to job insecurity. The gained insights may contribute to a more sustainable work participation of employees and may increase managerial awareness about the possible individual outcomes of job insecurity.

\section{Methods}

\subsection{Sampling and procedures}

Data were drawn from the ongoing Dutch prospective Maastricht Cohort Study (MCS), which started in May 1998 and was conducted in line with the ethical standards of the Declaration of Helsinki [49]. The MCS studies fatigue among workers and is carried out by Maastricht University [49]. The objectives of the MCS are fourfold, namely "(1) to gain insight into the prevalence and incidence of prolonged fatigue in the working population, (2) to identify risk factors involved in the onset and natural course of fatigue in the working population, (3) to investigate the diagnosis of fatigue, and (4) to study the effectiveness of different treatments of fatigue" [49].

Although the data of the MCS were not specifically collected for the analyses in the present study. I believe that there are no ethical issues involved in the use of these data for this purpose.

Sampling of workers for the survey was performed by approaching firms and organizations in various industries to invite them to participate in the MCS [49]. After 45 organizations consented to participation, their employees were approached to participate in the MCS [49]. Eligible workers were males and females aged 18-65, who contractually worked at least 16 hours per week [49]. Workers with a temporary contract were excluded [49]. This resulted in approximately 27,000 potential participants [49].

At baseline measurement, 12,140 participants aged 18 to 65 years, working at 45 different Dutch organizations in various sectors (civil service, education, healthcare, industry, public transport, services, and transport) with at least 100 workers were included in the MCS, providing a large and heterogeneous population $[50,51]$.

In the present study, the measurement in October $2012(N=4,783)\left(\mathrm{T}_{1}\right)[52]$ was selected as study baseline, because it was accompanied with an extension of the MCS that included various concepts required for this study. The follow-up period was two years, defining the October $2014\left(\mathrm{~T}_{2}\right)$ wave as follow-up. At this next measurement, subjects who earlier reported permanent retirement were no longer sent questionnaires. Of the targeted cohort participants who were presumed to be still employed $(n=3,450), 2,945$ ( 85 $\%)$ responded [52].

To establish a homogenous sample, strict inclusion and exclusion criteria were applied. Eligible participants worked at least 26 hours per week and reported an unchanged work situation at $\mathrm{T}_{2}$ (in terms of employer, type of employment, primary responsibilities, and contractual conditions such as working hours and shift work) compared to study baseline. For additional verification, if the organization name changed at $T_{2}$, efforts were made to investigate its cause. Respondents were only included if a new organization name was adopted that did not result from mergers that could have profoundly 
influenced policies, culture, and labor relations. Permanent employment may provide higher levels of predictability, control, and stability, which may result in lower perceived job insecurity, whereas this may be lower among workers with temporary contracts [11, 53]. Therefore, only participants with a permanent contract were included. Furthermore, eligible respondents participated in study baseline and follow-up, had no missing values, did not report "unknown" or "not applicable" for organization size at $\mathrm{T}_{1}$, and did not report "not applicable" for productivity loss at both $\mathrm{T}_{1}$ and $\mathrm{T}_{2}$. Participants were excluded when having multiple jobs, (partial) retired, (partial) sickness or disability benefits, sabbatical leave, pregnant, pregnancy leave, (partial) parental leave, or being self-employed. This resulted in a sample of 928 (32 $\%)$ participants at study baseline.

\subsection{Measures}

Job insecurity was measured with the self-report item "Do you fear to lose your job in the foreseeable future?" (no, yes), translated from the Questionnaire on the Experience and Evaluation of Work (QEEW) $[54,55]$. The instrument provides insight into how workers perceive their work and well-being. The dataset only contained job insecurity as a single binary variable.

Job performance was gauged using two measures, to address the limitation of studies employing different operationalizations for this multidimensional construct, which may explain the inconsistent findings $[12,13,56]$. First, individual core task performance was measured using four items from Dyne et al. [57]. To facilitate self-report, items were reformulated from the perspective of supervisor to the employee. The items "I fulfil the responsibilities specific to my job description", "I perform the tasks that are expected as part of the job", "I meet performance expectations", and "I adequately complete responsibilities" were rated on a scale from 1 ("Completely disagree") to 7 ("Completely agree"). The Cronbach alpha coefficient was 0.94 at $T_{1}$ and 0.95 at $\mathrm{T}_{2}$. Second, productivity loss was measured with the self-report item "My current productivity has compared to one year ago" from Fouarge et al. [58]. To avoid unsubstantiated ratings, the original scale was modified from 100 points to four categories ("decreased", "remain unchanged", "increased", and "not applicable"). The conceptual difference between these operationalizations is the applicable reference. The primary focus of core task performance is the evaluation of achieving minimum outputs that are formalized in job descriptions [29]. Productivity loss is however a broader and more subjective concept that, in addition to formalized core task performance, also considers prior productivity levels. Therefore, a worker reporting productivity loss may still perform the required work, but at a lower level of productivity than before.

\subsection{Confounders}

Analyses were adjusted for personal characteristics and work-related factors, measured by self-report at $\mathrm{T}_{1}[16,59]$. Personal characteristics include gender, age, household composition ("Do you live alone?" no, yes), and highest level of education achieved in 2012 that is categorized as low (elementary and lower vocational school), medium (lower secondary, intermediate vocational, and secondary school), and high (higher vocational school and university) [52].

Work-related factors include regular working hours (between 07:00 and 19:00, no, yes), physical job demands ("Do you consider your work physically very strenuous?" no, yes) translated from the Questionnaire on Work and Health [60], and emotional job demands ("Are you in your work often confronted with things that touch you personally?" no, yes) from the QEEW $[54,55]$ that was translated and slightly modified to emphasize the frequency "often". Psychological job demands were measured with five self-report items from the validated Dutch version of the Job Content Questionnaire (JCQ) [61, 62]. Items were rated from 1 ("Completely disagree") to 4 ("Completely agree"). An example item is "I have sufficient time to finish my work". Decision latitude was measured as the sum of the subscales decision authority and skill discretion; its self-report items were also derived from the Dutch version of the JCQ and were rated equally. Decision authority was measured using three items (e.g., "My job allows me to make many decisions myself.") and skill discretion was gauged with six items (e.g., "My job requires that I learn new things.”).

\subsection{Statistical analyses}

Data were analyzed for inclusion and exclusion criteria. The presence of Type I errors (i.e. false positives, e.g., pregnant males) was verified, and entries with impossible combinations were eliminated. 


\subsubsection{Cross-sectional analyses}

Linear regression analysis was performed to test the cross-sectional association between job insecurity and core task performance at $\mathrm{T}_{1}$. In addition, logistic regression analysis was used to assess the association between job insecurity and productivity loss at $\mathrm{T}_{1}$. For productivity loss, the categories "remain unchanged" and "increased" were grouped and treated as the reference category. In both analyses, two models were used to estimate the association. Model 1 estimated the association between job insecurity and the dependent variable at $\mathrm{T}_{1}$, and adjusted for personal characteristics. Model 2 additionally adjusted the estimates for work-related factors.

\subsubsection{Longitudinal analyses}

Longitudinal effects of job insecurity on core task performance at two-year follow-up were investigated using linear regression analysis. Four models were used to estimate the relationship. Model 1 estimated the relationship between job insecurity at $T_{1}$ and core task performance at $T_{2}$, and adjusted for personal characteristics. Model 2 in addition adjusted the estimates for work-related factors. In line with the stepwise approach specified by Aiken et al. [63], model 3 in addition controlled for core task performance at $\mathrm{T}_{1}$, and job insecurity at $\mathrm{T}_{2}$ was additionally controlled for in model 4.

Logistic regression analysis was performed to assess the relationship between job insecurity and productivity loss at two-year follow-up. Participants who reported productivity loss at $\mathrm{T}_{1}$ were excluded, resulting in a dataset of 870 subjects. Three models were used to estimate the relationship. Model 1 estimated the effect of job insecurity at $T_{1}$ and productivity loss at $\mathrm{T}_{2}$, and adjusted for personal characteristics. In model 2 , the estimates were additionally adjusted for work-related factors. Model 3 in addition controlled for job insecurity at $T_{2}$. Since respondents who reported productivity loss at $\mathrm{T}_{1}$ were excluded, controlling for these baseline levels was not meaningful.

\subsubsection{Duration analyses}

The two-year duration of exposure to job insecurity was computed using four ordinal values: Chronic (insecure at both $\mathrm{T}_{1}$ and $\mathrm{T}_{2}$ ), previous (insecure at $\mathrm{T}_{1}$, but not at $\mathrm{T}_{2}$ ), recent (insecure at $\mathrm{T}_{2}$, but not at $\mathrm{T}_{1}$ ), and never (not insecure at $\mathrm{T}_{1}$ or $\mathrm{T}_{2}$ ). Respondents categorized as never job insecure were treated as the reference category.
The relationship between the duration of job insecurity and core task performance at two-year follow-up was investigated using linear regression analysis, and was estimated using three models. Model 1 estimated the relationship between the duration of job insecurity and core task performance at $T_{2}$, and adjusted for personal characteristics. Model 2 in addition adjusted the estimates for work-related factors, and model 3 additionally controlled for core task performance at $\mathrm{T}_{1}$.

Logistic regression analysis was performed to assess the relationship between the duration of job insecurity and productivity loss at two-year followup. Participants who reported productivity loss at $T_{1}$ were excluded. Two models were used to estimate the relationship. Model 1 estimated the relationship of duration of job insecurity and productivity loss at $\mathrm{T}_{2}$, and adjusted for personal characteristics. Model 2 additionally adjusted the estimates for work-related factors.

For all analyses, data were verified to meet the specific underlying statistical assumptions. Data were analyzed using SPSS Statistics (Version 24.0; Armonk, NY: IBM Corp).

\section{Results}

\subsection{Descriptive results}

Table 1 presents the population characteristics at study baseline. The majority of participants were older and male; relatively few people reported job insecurity. Two-year exposure to chronic job insecurity was 4.1 percent, while more than 80 percent was identified as not insecure over two years. Selfreported core task performance was very high. Compared to the foregoing year, productivity of the majority of respondents remained unchanged, more than one-fifth perceived an increase, and 6.3 percent reported productivity loss.

\subsection{Cross-sectional results}

Job insecurity was not associated with core task performance at study baseline (Table 2). In contrast, job insecurity was associated with a more than two times larger productivity loss. The association remained significant after adjusting for personal and work-related factors. Therefore, in the cross-sectional timeframe, job insecurity was associated only with productivity loss. 
Table 1

Study population at baseline measurement (October 2012) $(n=928)$

\begin{tabular}{|c|c|c|c|}
\hline & $\%$ & M & SD \\
\hline \multicolumn{4}{|l|}{ Gender } \\
\hline Male & 78.7 & & \\
\hline Female & 21.3 & & \\
\hline Age & & 52.8 & 5.6 \\
\hline \multicolumn{4}{|l|}{ Living alone } \\
\hline Yes & 10.3 & & \\
\hline No & 89.7 & & \\
\hline \multicolumn{4}{|l|}{ Education level achieved in 2012} \\
\hline Low & 2.0 & & \\
\hline Medium & 20.4 & & \\
\hline High & 77.6 & & \\
\hline \multicolumn{4}{|l|}{ Average working hours per week } \\
\hline More than 40 hours & 24.5 & & \\
\hline $36-40$ hours & 54.1 & & \\
\hline 26-35 hours & 21.4 & & \\
\hline \multicolumn{4}{|l|}{ Regular working hours } \\
\hline Yes & 87.9 & & \\
\hline No & 12.1 & & \\
\hline \multicolumn{4}{|l|}{ Frequent work at night (after 11:00 PM) } \\
\hline Yes & 10.1 & & \\
\hline No & 89.9 & & \\
\hline \multicolumn{4}{|l|}{ Physical job demands } \\
\hline Yes & 18.3 & & \\
\hline No & 81.7 & & \\
\hline \multicolumn{4}{|l|}{ Emotional job demands } \\
\hline Yes & 23.2 & & \\
\hline No & 76.8 & & \\
\hline Psychological job demands (12-48) & & 31.8 & 5.7 \\
\hline Decision latitude (24-96) & & 76.3 & 9.7 \\
\hline Decision authority (12-48) & & 38.0 & 6.2 \\
\hline Skill discretion (12-48) & & 38.3 & 4.8 \\
\hline \multicolumn{4}{|l|}{ Organization size of all national offices } \\
\hline $1-9$ employees & 0.8 & & \\
\hline $10-49$ employees & 4.3 & & \\
\hline $50-249$ employees & 8.1 & & \\
\hline $250-499$ employees & 10.9 & & \\
\hline $500-1999$ employees & 35.3 & & \\
\hline 2000 or more & 40.6 & & \\
\hline \multicolumn{4}{|l|}{ Job insecurity } \\
\hline Yes & 12.2 & & \\
\hline No & 87.8 & & \\
\hline \multicolumn{4}{|c|}{ Duration of job insecurity (between 2012 and 2014) ${ }^{\mathrm{a}}$} \\
\hline Chronic & 4.1 & & \\
\hline Previous & 8.1 & & \\
\hline Recent & 6.5 & & \\
\hline Never & 81.4 & & \\
\hline Core task performance (4-28) & & 25.3 & 3.4 \\
\hline \multicolumn{4}{|c|}{ Productivity loss (compared to one year ago) ${ }^{\mathrm{a}}$} \\
\hline Decreased & 6.3 & & \\
\hline Remain unchanged & 71.7 & & \\
\hline Increased & 22.1 & & \\
\hline
\end{tabular}

\subsection{Longitudinal results}

Job insecurity was not related with core task performance two years later (Table 3). However, the relationship between job security and productivity loss two years later was significant $(p=0.050)$ (Table 4). At $\mathrm{T}_{2}$, productivity loss was more than two times larger. 
Table 2

Linear regression coefficients for cross-sectional association between job insecurity and core task performance, and logistic regression coefficients for cross-sectional association between job insecurity and productivity loss ${ }^{\mathrm{a}}$ (October 2012) $(n=928)$

\begin{tabular}{|c|c|c|c|c|c|c|c|c|c|c|c|c|c|c|}
\hline & \multicolumn{6}{|c|}{ Core task performance } & \multicolumn{8}{|c|}{ Productivity loss } \\
\hline & \multicolumn{3}{|c|}{ Model 1} & \multicolumn{3}{|c|}{ Model 2} & \multicolumn{4}{|c|}{ Model 1} & \multicolumn{4}{|c|}{ Model 2} \\
\hline & \multirow[b]{2}{*}{$\beta$} & \multirow[b]{2}{*}{ SE } & \multirow[b]{2}{*}{$p$} & \multirow[b]{2}{*}{$\beta$} & \multirow[b]{2}{*}{ SE } & \multirow[b]{2}{*}{$p$} & \multirow[b]{2}{*}{ OR } & \multirow[b]{2}{*}{$p$} & \multicolumn{2}{|c|}{$95 \% \mathrm{CI}$} & \multirow[b]{2}{*}{ OR } & \multirow[t]{2}{*}{ 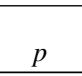 } & \multicolumn{2}{|c|}{$95 \% \mathrm{CI}$} \\
\hline & & & & & & & & & Lower & Upper & & & Lower & Upper \\
\hline Job insecurity & -0.035 & 0.341 & 0.289 & -0.022 & 0.337 & 0.490 & $2.378^{* *}$ & 0.009 & 1.243 & 4.551 & $2.232^{*}$ & 0.019 & 1.141 & 4.367 \\
\hline
\end{tabular}

Model 1, relationship of job insecurity at 2012 and the dependent variable at 2012; adjusted for personal characteristics: gender, age, living alone, and education achieved in 2012. Model 2, additionally adjusted for work-related factors: regular working hours, physical job demands, emotional job demands, psychological job demands, and decision latitude. $\beta$, Standardized Beta. SE, Standard Error. OR, Odds Ratio. $95 \%$ CI, 95 percent Confidence Interval. ${ }^{a}$ Remain unchanged and increased were grouped, and treated as reference category. ${ }^{*} p<0.05 ;{ }^{* *} p<0.01$; $* * * p<0.001$.

Table 3

Linear regression coefficients for relationship of both job insecurity and duration of job insecurity with core task performance at two-year follow-up (October 2012 to October 2014) $(n=928)$

\begin{tabular}{|c|c|c|c|c|c|c|c|c|c|c|c|c|}
\hline & \multicolumn{3}{|c|}{ Model 1} & \multicolumn{3}{|c|}{ Model 2} & \multicolumn{3}{|c|}{ Model 3} & \multicolumn{3}{|c|}{ Model 4} \\
\hline & $\beta$ & SE & $p$ & $\beta$ & SE & $p$ & $\beta$ & SE & $p$ & $\beta$ & SE & $p$ \\
\hline Job insecurity & 0.010 & 0.361 & 0.764 & 0.021 & 0.360 & 0.511 & 0.027 & 0.350 & 0.401 & 0.025 & 0.364 & 0.452 \\
\hline Duration of job insecurity & & & & & & & & & & & & \\
\hline Never $(n=755)$ (reference) & 0 & & & 0 & & & 0 & & & & & \\
\hline Chronic $(n=38)$ & 0.029 & 0.597 & 0.373 & 0.045 & 0.595 & 0.169 & 0.037 & 0.580 & 0.246 & & & \\
\hline Previous $(n=75)$ & -0.010 & 0.435 & 0.758 & -0.006 & 0.432 & 0.855 & 0.006 & 0.421 & 0.840 & & & \\
\hline Recent $(n=60)$ & -0.017 & 0.484 & 0.598 & -0.013 & 0.482 & 0.685 & -0.011 & 0.469 & 0.742 & & & \\
\hline
\end{tabular}

Model 1, relationship of the independent variable at 2012 and core task performance at 2014; adjusted for personal characteristics: gender, age, living alone, and education achieved in 2012. Model 2, additionally adjusted for work-related factors: regular working hours, physical job demands, emotional job demands, psychological job demands, and decision latitude. Model 3, additionally controlled for core task performance at 2012. Model 4, additionally controlled for job insecurity at 2014. $\beta$, Standardized Beta. SE, Standard Error. ${ }^{*} p<0.05$; ${ }^{* *} p<0.01 ;{ }^{* * *} p<0.001$.

Table 4

Logistic regression coefficients for relationship of both job insecurity and duration of job insecurity with productivity loss ${ }^{\mathrm{a}}$ at two-year follow-up (October 2012 to October 2014) $(n=870)$

\begin{tabular}{|c|c|c|c|c|c|c|c|c|c|c|c|c|}
\hline & \multicolumn{4}{|c|}{ Model 1} & \multicolumn{4}{|c|}{ Model 2} & \multicolumn{4}{|c|}{ Model 3} \\
\hline & \multirow[b]{2}{*}{ OR } & \multirow[b]{2}{*}{$p$} & \multicolumn{2}{|c|}{$95 \% \mathrm{CI}$} & \multirow[b]{2}{*}{ OR } & \multirow[b]{2}{*}{$p$} & \multicolumn{2}{|c|}{$95 \% \mathrm{CI}$} & \multirow[b]{2}{*}{ OR } & \multirow[b]{2}{*}{$p$} & \multicolumn{2}{|c|}{$95 \% \mathrm{CI}$} \\
\hline & & & Lower & Upper & & & Lower & Upper & & & Lower & Upper \\
\hline Job insecurity & 1.881 & 0.104 & 0.877 & 4.034 & 1.767 & 0.154 & 0.808 & 3.865 & 2.264 & 0.050 & 1.000 & 5.125 \\
\hline \multicolumn{13}{|l|}{ Duration of job insecurity } \\
\hline Never $(n=715)$ (reference) & 0 & & & & 0 & & & & & & & \\
\hline Chronic $(n=33)$ & 1.099 & 0.901 & 0.251 & 4.805 & 0.909 & 0.900 & 0.203 & 4.062 & & & & \\
\hline Previous $(n=66)$ & 2.151 & 0.080 & 0.913 & 5.071 & 2.137 & 0.091 & 0.887 & 5.152 & & & & \\
\hline Recent $(n=56)$ & 0.282 & 0.222 & 0.037 & 2.154 & 0.256 & 0.191 & 0.033 & 1.971 & & & & \\
\hline
\end{tabular}

Model 1, relationship of the independent variable at 2012 and productivity loss at 2014; adjusted for personal characteristics: gender, age, living alone, and education achieved in 2012. Model 2, additionally adjusted for work-related factors: regular working hours, physical job demands, emotional job demands, psychological job demands, and decision latitude. Model 3, additionally controlled for job insecurity at 2014. OR, Odds Ratio. 95 \% CI, 95 percent Confidence Interval. ${ }^{a}$ Remain unchanged and increased were grouped, and treated as reference category. ${ }^{*} p<0.05 ;{ }^{* *} p<0.01 ;{ }^{* * *} p<0.001$.

\subsection{Duration results}

The duration of job insecurity (chronic, previous, and recent) did not predict core task performance (Table 3) or productivity loss (Table 4) two years later.

In sum, results indicate that short-term, job insecurity was only associated with productivity loss at study baseline, but not with core task performance. In addition, job insecurity only predicted productivity loss at two-years follow-up, but it did not predict core task performance. Furthermore, chronic job insecurity did not result in lower levels of core task performance or in most productivity loss. 


\section{Discussion}

This study investigated the effect of time in explaining the conflicting relationship of perceived job insecurity and perceived job performance using longitudinal data of a large homogenous sample. In addition, the influence of two-year exposure to job insecurity on job performance was examined, and it was hypothesized that chronic job insecurity negatively impacts job performance most. To address the limitations of earlier research, job performance was operationalized as core task performance and as productivity loss.

First, cross-sectional results suggest that job insecurity was associated with a more than doubled risk for productivity loss. Furthermore, results indicate that job insecurity was not associated with more core task performance. This finding may suggest that when feeling job insecure, employees still perform the required work, but at a lower level of productivity than before. These findings contradict the literature regarding the "short-term managerial view" [38-40], which says that job insecure workers are likely to increase their job performance to avoid involuntary job loss [1]. Instead, the findings corroborate other scholars $[12,42,43]$ regarding stress-related theories, and suggest that applying the stressor job insecurity to workers as motivational strategy may actually impede job performance in the short-term, while employees are likely to still maintain the minimum performance required by their job profile.

Second, longitudinal analyses showed that job insecurity was not related with higher core task performance. However, a significant causal effect of job insecurity on productivity loss two years later was observed, resulting in a more than doubled productivity loss. The latter finding suggests that experiencing job insecurity can indeed exhaust available resources to cope with experienced job insecurity long-term, which eventually results in decreased job performance [12, 42, 43]. This finding corroborates other researchers who reported that job insecurity can be harmful [1, 11, 19, 41]. Furthermore, this finding is remarkable, because it specifically implies that experiencing job insecurity can adversely impact job performance several years into the future. Similarly, from a managerial perspective, this finding may suggest that job insecurity should be avoided, since it can reduce the performance of the individual worker, and thereby also impact the performance of the entire organization. Therefore, I conclude that job insecurity resulted in a decreased productivity two-years later, while the worker was likely to maintain the least required performance as defined by their job profile.

To illustrate the observed importance of time in these relationships, Barrech et al. [64] found in a similar study on well-being that experienced job insecurity has a significant long-term influence on subjective well-being 20 years later when the individual was retired, and corrected their analyses for a wide range of potential confounders. In addition, to more accurately measure the concepts in the present study, job insecurity and job performance were assessed using self-report by the employee. The importance of perceptions is also illustrated by a Danish study among slaughterhouse workers [65], which reports that the perception of one's own working conditions was clearly associated with sickness absence.

Contrary to the reported findings, the literature however suggests that job performance may not be the direct consequence of job insecurity, but that the relationship may be mediated instead [27, 66]. In this light, Shoss [67] recently published a conceptual model that positions performance as a rather distal outcome of job insecurity, of which the causal relationship is assumed to be mediated by stress-related mechanisms. Therefore, engaging in tactics such as impression management, to cope with stress, anxiety, and discomfort resulting from the threatening job insecurity, and attempting to gain control by altering the image of the employee perceived by his supervisor, may increase task-irrelevant cognitions and behavior, shift attention, and decrease the worker's concentration [13, 41, 68-70]. These coping activities and perceptions of job insecurity require time and ongoing effort that may eventually drain the employee's energy, resulting in increased psychological distress and prolonged fatigue [12, 13, 71]. Prolonged fatigue refers to the cognitive, emotional, and behavioral subjective experience of persistent exhaustion [50], and often involves abandoning work [72]. The proposed negative longitudinal relationship between job insecurity and job performance may therefore be better understood when the mediating effect of prolonged fatigue is considered. When fatigue has accumulated as a result of experienced stress, less energy may be available to maintain performance at work, which may subsequently exert a negative influence on job performance $[12,49,50,73$, 74]. In line with the JD-R Model, prolonged fatigue may therefore act as an important mediator between the stressor and outcome, which helps to better understand the precise pathway between job insecurity and job performance. 
Third, duration analyses found no longitudinal relationships between the two-year duration of exposure to job insecurity (chronic, previous, and recent), and core task performance or productivity loss. In addition, compared to other lengths of job insecurity, chronic job insecurity, where the worker was job insecure at both $T_{1}$ and $T_{2}$, did not significantly predict the least job performance. This finding contradicts Glavin [48], who proposed that the nature and severity of outcomes may be influenced by the length of exposure to job insecurity, and found that mainly chronic job insecure workers suffer from decreased health. Their finding is in line with the JD-R Model $[75,76]$, that positions job-related strain (i.e. job insecurity) as outcome of the interaction of job demands and job resources (e.g., the level of education and employability). Instead, the findings suggest that the factor time, operationalized as the duration of job insecurity over two years, may not have a role in these relationships.

Establishing the duration of job insecurity using two measurements at two-year follow-up may however been insufficient to precisely determine chronic exposure over two years. Therefore, this follow-up period was perhaps too long. As a result, the evolution and fluctuation of job insecurity during the intermediate years, and the continuous presence of job insecurity over two years, was difficult to establish.

\subsection{Strengths and limitations}

This study had three noteworthy strengths.

First, in line with the literature, and to provide a more trustworthy measurement of the constructs, job insecurity and job performance were conceptualized as the self-reported perception. Self-rated perceptions by the employee were considered optimal because, contrary to objective measures reported externally (e.g., by his supervisor or colleagues), the former considered the conscious and unconscious thoughts, feelings, and emotions of the individual employee. This information was required to understand and predict employee behavior [23-26]. However, to overcome potential same-source bias in self-reported job performance, future studies should also consider supervisor judgments.

Second, to address the shortcoming that job performance in literature often is operationalized differently $[12,13,56]$, and that researchers therefore may yield inconsistent results, this study operationalized this multidimensional construct as core task performance and as productivity loss. Results indicate that is was beneficial to investigate both operationalizations, since the results indeed yielded more insight into these two dimensions of job performance.

Third, the study has a large sample and a longitudinal design, which facilitated the estimation of the effect of time on the relationship of job insecurity and job performance.

This study also has several limitations.

First, the majority of participants $(87.8 \%)$ reported no job insecurity, 81.4 percent was not job insecure over two years, and only 4.1 percent was identified as chronic job insecure. Furthermore, in the Netherlands, where stringent occupational dismissal law applies to permanent contracts, royal unemployment benefits exist, and employers are obligated to bear full (financial) responsibility for their employees during the initial two years of sickness absence, perceived job insecurity may be lower than elsewhere. Therefore, the sample may not represent precarious workers, but was instead populated by a majority of employees reporting no job insecurity, and who are employed in a social and political environment that stimulates and enforces the reduction of job insecurity. The reported findings have limited external validity and should without proper consideration not be generalized to other populations nor to workers in other countries.

Second, similar to the presence of job insecurity, the sample was homogenous but not distributed evenly with regard to several characteristics, which may influence the internal and external validity of the reported findings. The majority of participants were male $(78.7 \%)$, had a higher mean age (52.8 years), were highly educated $(77.6 \%$ ) while only 2.0 percent had a low educational level, and 87.9 percent worked regular hours. Therefore, without proper consideration, findings should not be generalized to female, young, or low educated workers, nor to employees with irregular working hours.

Third, because the questionnaire used in October 2012 (study baseline) was extended with constructs required for this study, and only data of one subsequent follow-up (October 2014) was yet available, it was not possible to examine different follow-up periods, to analyze fluctuations and trends in selfreported ratings over multiple years, nor to calculate other durations of exposure to job insecurity.

Finally, the potential presence of the healthy worker effect cannot be ruled out completely. As previously discussed, no new participants were accepted once the MCS had commenced in 1998. Because these subjects still participated in this cohort study 
14 (in 2012) and 16 (in 2014) years later, and were still employed in 2016 (although not necessarily the same employer as in 1998), this may indicate that respondents have been able to successfully withstand or adjust to the situations that they were confronted with in the intermediate years.

\subsection{Conclusions and implications}

To conclude, job insecurity was only associated with productivity loss short-term. No evidence was found for the association with core task performance. Job insecurity only predicted productivity loss at two-year follow-up, but was not related with core task performance. For both timeframes, job insecurity consistently had a more than two times larger effect on productivity loss. However, the duration of job insecurity, and in particular chronic job insecurity, did not predict core task performance or productivity loss two years later. The factor time, operationalized as time of follow-up and as the duration of exposure to job insecurity, did not provide more clarity concerning the conflicting views.

In practice, supervisors should reconcile to be more reluctant toward utilizing debatable motivational strategies that aim to increase job performance by applying job insecurity to their workers. Given the observed strong effect of job insecurity on productivity loss, both short-term and long-term, the large theoretical ambiguity about the nature of this association, the scarcity of literature addressing the longitudinal relationship, and given the existing and abundant evidence that job insecurity has a negative long-term impact on health-related outcomes, such motivational strategies may not be beneficial, and may instead unintendedly impede individual and organizational performance. Until such motivational strategies are found harmless, supervisors and workers should remain cautious and ought to consider avoiding job insecurity where possible. In addition, the findings have limited external validity and should without proper consideration not be generalized to female, young, or low educated workers, to employees working irregular hours, to other populations than were studied, nor to workers in other countries.

Based on the reported advancements, I first recommend the investigation of long-term relationships using a follow-up shorter than two years. Second, research addressing the duration of job insecurity remains scarce. Further research should therefore investigate the duration of the experienced job insecurity using a timeframe shorter than two years, and should examine the subsequent effect on perceived job performance. Third, the mediating role of prolonged fatigue, which is suggested by, and fits well in, existing health-related literature, should receive more theoretical attention. The measurement should preferably include three data waves, where job insecurity is examined at $T_{1}$, prolonged fatigue is assessed at $T_{2}$, and job performance is investigated at $\mathrm{T}_{3}$. Fourth, future studies should also investigate the importance of buffers (i.e. the level of education, perceived employability, age, and gender) in these relationships. Lastly, given that applicable protective public policy provisions and strictly enforced occupational dismissal legislation in the Netherlands may decrease job insecurity, cross-national replication of this study could gain more insight into the effects of such national programs on the perceived job insecurity and on the subsequent perceived job performance of workers.

\section{Acknowledgments}

The author would like to thank Prof. Dr. IJmert Kant and Dr. Dave Stynen from the Department of Epidemiology at Maastricht University for access to the data of the Maastricht Cohort Study and for their critical comments on early drafts of this manuscript.

\section{Availability of data and materials}

The data that support the findings of this study are available from the Department of Epidemiology at Maastricht University, but restrictions apply to the availability of these data, which were used under license for the current study, and so are not publicly available.

\section{Conflict of interest}

The author has declared to have no competing interests.

\section{References}

[1] Staufenbiel T, König CJ. A model for the effects of job insecurity on performance, turnover intention, and absenteeism. Journal of Occupational and Organizational Psychology. 2010;83(1):101-17. 
[2] Greenhalgh L, Rosenblatt Z. Evolution of Research on Job Insecurity. Int Studies of Mgt \& Org. 2010;40(1):6-19.

[3] Schreurs BHJ, Van Emmerik H, Günter H, Germeys F. A weekly diary study on the buffering role of social support in the relationship between job insecurity and employee performance. Hum Resour Manage. 2012;51(2):259-79.

[4] Piccoli B, De Witte H. Job insecurity and emotional exhaustion: Testing psychological contract breach versus distributive injustice as indicators of lack of reciprocity. Work Stress. 2015;29(3):246-63.

[5] Berntson E, Näswall K, Sverke M. The moderating role of employability in the association between job insecurity and exit, voice, loyalty and neglect. Econ Ind Democracy. 2010;31(2):215-30.

[6] Tompa E, Scott-Marshall H, Dolinschi R, Trevithick S, Bhattacharyya S. Precarious employment experiences and their health consequences: Towards a theoretical framework. Work. 2007;28(3):209-24.

[7] Kinnunen U, Mäkikangas A, Mauno S, De Cuyper N, De Witte H. Development of Perceived Job Insecurity Across Two Years: Associations With Antecedents and Employee Outcomes. J Occup Health Psychol. 2014;19(2):243-58.

[8] Sverke M, De Witte H, Näswall K, Hellgren J. European perspectives on job insecurity: Editorial introduction. Econ Ind Democracy. 2010;31(2):175-8.

[9] European Union. Occupational health concerns: stressrelated and psychological problems associated with work. Brussels: Directorate General for Internal Policies; 2013.

[10] Cabeças JMM. Taxonomy to characterize occupational hazards (risk factors) at the workplace level. Work. 2015;51(4):703-13.

[11] Schaufeli WB. Job Insecurity Research is Still Alive and Kicking Twenty Years Later: A Commentary. Aust Psychol. 2016;51(1):32-5.

[12] Fischmann G, Sulea C, Kovacs P, Iliescu D, De Witte $\mathrm{H}$. Qualitative and quantitative job insecurity: relations with nine types of performance. Psihol Resur Um. 2015;13(2):152-64.

[13] Gilboa S, Shirom A, Fried Y, Cooper C. A MetaAnalysis of Work Demand Stressors and Job Performance: Examining Main and Moderating Effects. Pers Psychol. 2008;61(2):227-71.

[14] De Witte H, Pienaar J, De Cuyper N. Review of 30 Years of Longitudinal Studies on the Association Between Job Insecurity and Health and Well-Being: Is There Causal Evidence? Aust Psychol. 2016;51(1):18-31.

[15] Sverke M, Hellgren J, Näswall K. No Security: A Meta-Analysis and Review of Job Insecurity and Its Consequences. J Occup Health Psychol. 2002;7(3):242-64.

[16] Cheng GHL, Chan DKS. Who Suffers More from Job Insecurity? A Meta-Analytic Review. Appl Psychol. 2008;57(2):272-303.

[17] Wang H-j, Lu C-q, Siu O-l. Job Insecurity and Job Performance: The Moderating Role of Organizational Justice and the Mediating Role of Work Engagement. J Appl Psychol. 2015; 100(4):1249-58.

[18] Chirumbolo A, Areni A. Job insecurity influence on job performance and mental health: Testing the moderating effect of the need for closure. Econ Ind Democracy. 2010;31(2):195-214.

[19] Chirumbolo A, Areni A. The influence of job insecurity on job performance and absenteeism: The moderating effect of work attitudes. SA J Ind Psychol. 2005;31(4):65-71.

[20] De Witte H, De Cuyper N, Vander Elst T, Vanbelle E, Niesen W. Job Insecurity: Review of the Literature and a Summary of Recent Studies from Belgium. Romanian J Appl Psychol. 2012;14(1):11-7.

[21] Leka S, Jain A. Health Impact of Psychosocial Hazards at Work: An Overview. Geneva: World Health Organization; 2010.

[22] Bakker AB, Demerouti E. The Job Demands-Resources model: state of the art. J Manage Psychol. 2007;22(3):30928.

[23] Klandermans B, Van Vuuren T. Job Insecurity: Introduction. Eur J Work Org Psychol. 1999;8(2):145-53.

[24] Froggatt P. Short-term absence from industry: I Literature, definitions, data, and the effect of age and length of service. Br J Ind Med. 1970;27(3):199-210.

[25] Hinkle LE, Plummer N. Life stress and industrial absenteeism; the concentration of illness and absenteeism in one segment of a working population. Ind Med Surg. 1952;21(8):363-75

[26] Taylor PJ. Sickness Absence Resistance. Trans Soc Occup Med. 1968;18(2):96-100.

[27] Selenko E, Mäkikangas A, Mauno S, Kinnunen U. How does job insecurity relate to self-reported job performance? Analysing curvilinear associations in a longitudinal sample. Journal of Occupational and Organizational Psychology. 2013;86(4):522-42.

[28] Griffin MA, Neal A, Parker SK. A new model of work role performance: Positive behavior in uncertain and interdependent contexts. Acad Manage J. 2007;50(2):327-47.

[29] Becker TE, Kernan MC. Matching Commitment to Supervisors and Organizations to In-Role and Extra-Role Performance. Hum Perform. 2003;16(4):327-48.

[30] Koopmans L, Bernaards CM, Hildebrandt VH, Schaufeli WB, De Vet HCW, Van der Beek AJ. Conceptual Frameworks of Individual Work Performance: A Systematic Review. Journal of Occupational and Environmental Medicine. 2011;53(8):856-66.

[31] Murphy KR. Explaining the Weak Relationship Between Job Performance and Ratings of Job Performance. Ind Organ Psychol. 2008;1(2):148-60.

[32] Landy FJ, Farr JL. The measurement of work performance: Methods, theory, and applications. New York: Academic Press; 1983.

[33] Murphy KR, Cleveland JN. Understanding Performance Appraisal: Social, Organizational, and Goal-Based Perspectives. Thousand Oaks, CA: Sage; 1995.

[34] Landy FJ, Farr JL. Performance Rating. Psychological Bulletin. 1980;87(1):72-107.

[35] Katz D, Kahn RL. The Social Psychology of Organizations. 2nd ed. New York, NY: John Wiley; 1978.

[36] Ollo-López A, Bayo-Moriones A, Larraza-Kintana M. Not All Alike: The Distinctive Impact of Voluntary and Involuntary Effort on Stress and Fatigue. Appl Res Qual Life. 2014;9(3):559-73.

[37] Probst TM. Layoffs and Tradeoffs: Production, Quality, and Safety Demands Under the Threat of Job Loss. J Occup Health Psychol. 2002;7(3):211-20.

[38] Repenning NP. Drive out Fear (Unless You Can Drive It in): The Role of Agency and Job Security in Process Improvement. Manag Sci. 2000;46(11):1385-96.

[39] Van Vuuren T, Klandermans B, Jacobson D, Hartley J. Predicting employees' perceptions of job insecurity. In: Hartley J, Jacobson D, Klandermans B, Van Vuuren T, editors. Job insecurity: Coping with jobs at risk. London: Sage; 1991. p. 65-78.

[40] Borg I, Elizur D. Job Insecurity: Correlates, Moderators and Measurement. Int J Manpower. 1992;13(2):13-26. 
[41] Huang G-h, Zhao HH, Niu X-y, Ashford SJ, Lee C. Reducing Job Insecurity and Increasing Performance Ratings: Does Impression Management Matter? J Appl Psychol. 2013;98(5):852-62.

[42] Ashford SJ, Lee C, Bobko P. Content, cause, and consequences of job insecurity: A theory-based measure and substantive test. Acad Manage J. 1989;32(4):803-29.

[43] Wong Y-T, Wong C-S, Ngo H-Y, Lui H-K. Different responses to job insecurity of Chinese workers in joint ventures and state-owned enterprises. Hum Relat. 2005;58(11):1391-418.

[44] Ferrie JE, Shipley MJ, Stansfeld SA, Marmot MG. Effects of chronic job insecurity and change in job security on self reported health, minor psychiatric morbidity, physiological measures, and health related behaviours in British civil servants: the Whitehall II study. Journal of Epidemiology and Community Health. 2002;56(6):450-4.

[45] Ferrie JE, Shipley MJ, Marmot MG, Stansfeld S, Smith GD. The health effects of major organisational change and job insecurity. Soc Sci Med. 1998;46(2):243-54.

[46] Kasl SV, Jones BA. An epidemiological perspective on research designs, measurement and surveillance strategies. In: Quick JC, Tetrick LE, editors. Handbook of Occupational Health Psychology. Washington, DC: American Psychological Association; 2002.

[47] Swaen GMH, Bültmann U, Kant I, Van Amelsvoort LGPM. Effects of Job Insecurity From a Workplace Closure Threat on Fatigue and Psychological Distress. Journal of Occupational and Environmental Medicine. 2004;46(5): 443-9.

[48] Glavin P. Perceived Job Insecurity and Health: Do Duration and Timing Matter? Sociol Q. 2015;56(2):300-28.

[49] Mohren D, Jansen N, Van Amelsvoort L, Kant I. An Epidemiological Approach of Fatigue and Work: Experiences from the Maastricht Cohort Study. Maastricht: Programma Epidemiologie van Arbeid en Gezondheid; 2007.

[50] Kant I, Bültmann U, Schröer KAP, Beurskens AJHM, Van Amelsvoort LGPM, Swaen GMH. An epidemiological approach to study fatigue in the working population: the Maastricht Cohort Study. Occupational and Environmental Medicine. 2003;60(Suppl 1):i32-i9.

[51] Szerencsi K, Van Amelsvoort L, Serroyen J, Prins M, Jansen $\mathrm{N}$, Kant I. The impact of personal attributes on the association between cumulative exposure to work stressors and cardiovascular disease. J Psychosom Res. 2013;75(1):2331.

[52] Stynen D, Jansen NWH, Slangen JJM, Kant I. Impact of Development and Accommodation Practices on Older Workers' Job Characteristics, Prolonged Fatigue, Work Engagement, and Retirement Intentions Over Time. Journal of Occupational and Environmental Medicine. 2016;58(11):1055-65.

[53] Hoefsmit N, Cleef K. If it isn't finished at five, then I'll continue until it is. A qualitative study of work pressure among employees in vocational education. Work. 2018;61(1):6980.

[54] Van Veldhoven M, Meijman T. Het Meten van Psychosociale Arbeidsbelasting met een Vragenlijst: De Vragenlijst Beleving en Beoordeling van de Arbeid (VBBA) [The Measurement of Psychosocial Job Demands with a Questionnaire: The Questionnaire Experience and Evaluation of Work (VBBA)]. Amsterdam: NIA; 1994.

[55] Van Veldhoven M, Broersen S. Measurement quality and validity of the "need for recovery scale". Occupational and Environmental Medicine. 2003;60(Suppl 1):i3-i9.
[56] Probst TM, Stewart SM, Gruys ML, Tierney BW. Productivity, counterproductivity and creativity: The ups and downs of job insecurity. Journal of Occupational and Organizational Psychology. 2007;80(3):479-97.

[57] Van Dyne L, LePine JA. Helping and Voice Extra-Role Behaviors: Evidence of Construct and Predictive Validity. Acad Manage J. 1998;41(1):108-19.

[58] Fouarge D, De Grip A, Montizaan R. Pensioenverwachtingen en personeelsbeleid: Verslag van de ROA enquête 2011 [Pension expectations and personnel policy: Report of the ROA survey 2011]. Maastricht: Researchcentrum voor Onderwijs en Arbeidsmarkt (ROA); 2012.

[59] Keim AC, Landis RS, Pierce CA, Earnest DR. Why Do Employees Worry About Their Jobs? A Meta-Analytic Review of Predictors of Job Insecurity. J Occup Health Psychol. 2014;19(3):269-90.

[60] Gründemann RWM, Smulders PWG, De Winter CR. Handleiding Vragenlijst Arbeid en Gezondheid [Manual Questionnaire on Work and Health]. Lisse: Swets \& Zeitlinger; 1993.

[61] Houtman I. Reliability and validity of the Dutch version of the Karasek Job Content Questionnaire. Washington, DC: NIOSH/APA conference on Stress, Work and Health; 1995.

[62] Karasek RA. The Job Content Questionnaire and User's Guide (version 1.1). Los Angeles: Department of Industrial and Systems Engineering, University of Southern California; 1985.

[63] Aiken LS, West SG. Multiple Regression: Testing and Interpreting Interactions. Thousand Oaks, CA: Sage; 1991.

[64] Barrech A, Baumert J, Emeny RT, Gündel H, Ladwig K-H. Mid-life job insecurity associated with subjective well-being in old age: results from the population-based MONICA/KORA study. Scand J Work Environ Health. 2016;42(2):170-4.

[65] Kristensen TS. Sickness absence and work strain among Danish slaughterhouse workers: An analysis of absence from work regarded as coping behaviour. Soc Sci Med. 1991;32(1):15-27.

[66] Vander Elst T, De Cuyper N, Baillien E, Niesen W, De Witte H. Perceived Control and Psychological Contract Breach as Explanations of the Relationships Between Job Insecurity, Job Strain and Coping Reactions: Towards a Theoretical Integration. Stress Health. 2016;32(2):100-16.

[67] Shoss MK. Job Insecurity: An Integrative Review and Agenda for Future Research. J Manage. 2017.

[68] Demerouti E, Taris TW, Bakker AB. Need for recovery, home-work interference and performance: Is lack of concentration the link? J Vocat Behav. 2007;71(2):204-20.

[69] Kavanagh J. Stress and Performance: A Review of the Literature and Its Applicability to the Military. Santa Monica, CA: RAND Corporation; 2005.

[70] Rosenfeld PR, Giacalone RA, Riordan CA. Impression management in organizations: Theory, measurement, and practice. New York, NY: Routledge; 1995.

[71] Dekker SWA, Schaufeli WB. The Effects of Job Insecurity on Psychological Health and Withdrawal: A Longitudinal Study. Aust Psychol. 1995;30(1):57-63.

[72] Hopstaken JF, Van der Linden D, Bakker AB, Kompier MAJ. A multifaceted investigation of the link between mental fatigue and task disengagement. Psychophysiology. 2015;52(3):305-15.

[73] Robert G, Hockey J. Compensatory control in the regulation of human performance under stress and high workload: A cognitive-energetical framework. Biol Psychol. 1997;45(1):73-93. 
[74] Wright RA, Patrick BM, Thomas C, Barreto P. When fatigue promotes striving: Confirmation that success importance moderates resource depletion influence on effort-related cardiovascular response. Biol Psychol. 2013;93(2):316-24.

[75] Demerouti E, Bakker AB, Nachreiner F, Schaufeli WB. The Job Demands-Resources Model of Burnout. J Appl Psychol. 2001;86(3):499-512.
[76] Schaufeli WB, Bakker AB. Job demands, job resources, and their relationship with burnout and engagement: a multisample study. J Organ Behav. 2004;25(3):293-315. 